Интернет-журнал «Науковедение» ISSN 2223-5167 http://naukovedenie.ru/

Том 7, №1 (2015) http://naukovedenie.ru/index.php?p=vol7-1

URL статьи: http://naukovedenie.ru/PDF/131TVN115.pdf

DOI: 10.15862/131TVN115 (http://dx.doi.org/10.15862/131TVN115)

УДК $\mathbf{5 4 2 . 0 7}$

Деменев Алексей Владимирович

ФГБОУ ВПО «Российский государственный университет туризма и сервиса»

Москва, Россия ${ }^{1}$

Кандидат технических наук, доцент кафедры сервиса

E-mail: saprmgus@mail.ru

Набережных Анатолий Иванович

ФГБОУ ВПО «Российский государственный университет туризма и сервиса»

Москва, Россия

Кандидат технических наук, профессор кафедры сервиса

E-mail: ntchausehold@gmail.com

Данилов Артем Игоревич

ФГБОУ ВПО «Российский государственный университет туризма и сервиса»

Москва, Россия

Аспирант кафедры сервиса

E-mail: danilov.tema@mail.ru

\title{
Охлаждение компрессора как фактор снижения шума бытового холодильника
}

${ }^{1}$ 141221, Московская обл., Пушкинский район, поселок Черкизово, ул. Главная, 99 
Аннотация. В бытовом холодильник компрессор является основным источником шума и теплоты, причем изолирование распространения звука от компрессора в воздушной среде приводит к повышению теплонапряженности его работы и существенному снижению энергоэффективности холодильника. Установка звукоизолирующего щитка перед кожухом компрессора позволяет снизить уровень шума. Система охлаждения масла в компрессоре получила широкое распространение в зарубежных и отечественных холодильниках, реализующий «тропический» температурный режим работы Варианты холодильных агрегатов испытывались при оптимальных дозах хладона и постоянной проходимости капиллярной трубки. Звукоизоляция кожуха компрессора приводит к некоторому повышению температуры рабочей обмотки электродвигателя и оптимизация дозы хладона при звукоизоляций кожуха компрессора позволит увеличить значение этих показателей. Результаты исследования подтверждают возможность снижения шума холодильника, за счет применения оптимизированного отвода теплоты от головки блока цилиндра компрессора.

Ключевые слова: компрессор; система охлаждения; холодопроизводительность; перегрев; холодильный коэффициент; звуковая мощность.

\section{Ссылка для цитирования этой статьи:}

Деменев А.В., Набережных А.И., Данилов А.И. Охлаждение компрессора как фактор снижения шума бытового холодильника // Интернет-журнал «НАУКОВЕДЕНИЕ» Том 7, №1 (2015) http://naukovedenie.ru/PDF/131TVN115.pdf (доступ свободный). Загл. с экрана. Яз. рус., англ. DOI: 10.15862/131TVN115 


\section{Введение}

Виброакустические характеристики являются важным показателем конкурентоспособности бытового холодильника как представителя бытовой техники [2], причем определяющее влияние на их генерирование оказывает герметичный хладоновый компрессор. Исследования герметичного компрессора, представляющий собой многоуровневый и многокомпонентный излучатель воздушного шума, реализованы в виде комплекса технических решений, позволяющих снизить уровень шума собственно компрессора до значений 38-36 дБА [1]. Акустические технические решения для снижения уровня шума, разделяются на: звукоизоляцию, звукопоглощение и звукоглушение.

\section{Технический уровень компрессора}

Известно звукоотражающее техническое решение, описанное в инструкции по эксплуатации холодильника ЗиЛ-63 [2]. В нижней части шкафа холодильника имеется углубление с размещенным в нем герметичным компрессором 1 и металлический щиток 3 , частично закрывающий машинный отсек, причем, внутренняя сторона щитка покрыта звукопоглощающим материалом.

Установка звукоизолирующего щитка перед кожухом компрессора позволяет снизить уровень шума на $1,5 \div 2,5 \partial Б а$, График снижения уровня шума по спектру звукопоглощающими щитками приводится в книге И. В. Болгов, Набережных А.И. и др. [6].

Установка звукоизолирующего щитка перед кожухом компрессора значительно повышает температурный уровень эксплуатации компрессора, что наглядно продемонстрировано исследованиями температурного поля тепловизором на рис 2. 


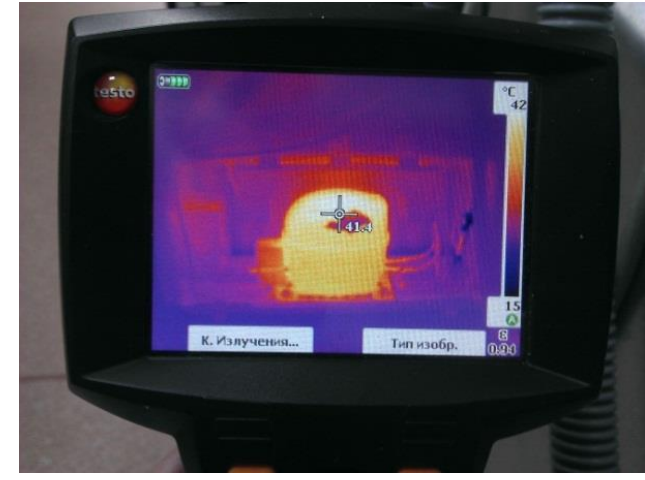

a)

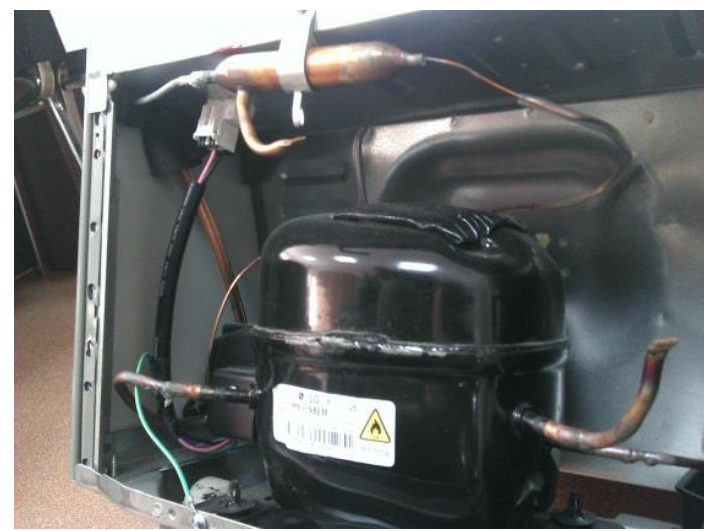

B)

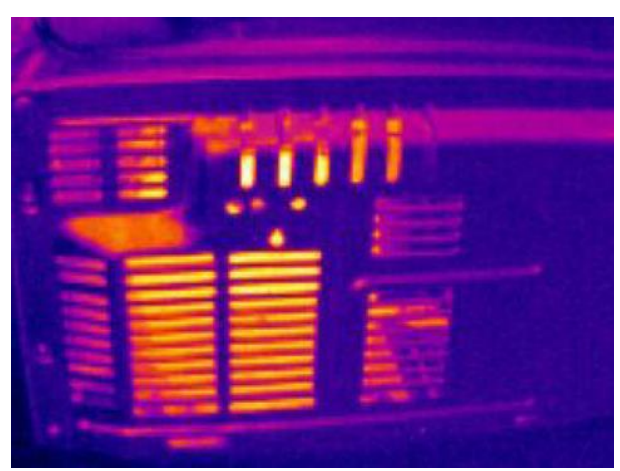

б)

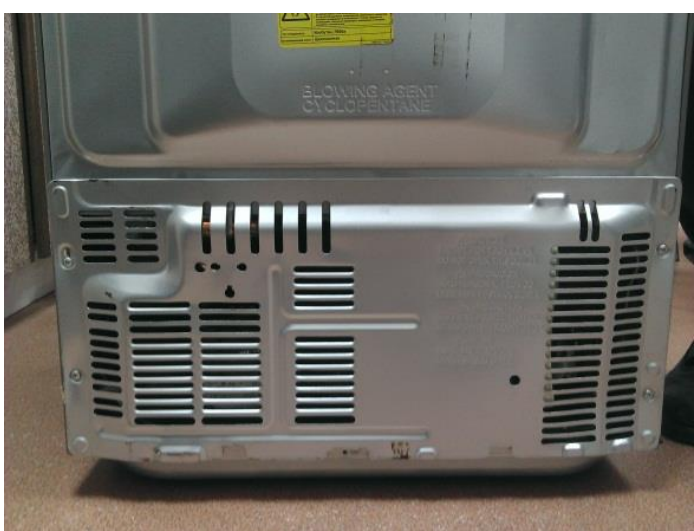

г)

Рисунок 2 Исследование холодильника LG модели GA-B409SLQ

а) Изображение экрана тепловизора; б) результаты тепловизорного сканирования; в) изображение холодильника без щиитк; г) изображение звукоизолирующего щчитка перед кожухом компрессора;

При работе герметичного хладового компрессора в нормированном температурном режиме $[4,5]$ температура рабочей обмотки электродвигателя достигает $120^{\circ} \mathrm{C}$, температура всасываемых паров в цилиндре $145 \div 155^{\circ} \mathrm{C}$, а температура сжатых паров $170 \div 190{ }^{\circ} \mathrm{C}$. Очевидно, что применение этих компрессоров в холодильниках с звуко и теплоизолированием компрессора, так же как и в тропическом исполнении без дополнительной системы охлаждения не приемлемо, так как температура обмоток электродвигателя превышает $130{ }^{\circ} \mathrm{C}$.

В бытовых холодильниках нашли свое применение следующие методы охлаждения герметичных компрессоров:

- всасываемыми парами холодильного агента;

- $\quad$ отвод тепла с поверхности кожуха путем внешнего обдува вентилятором;

- отвод тепла из кожухе путем подохлаждения масла жидким хладагентов из предконденсатора или тепловой трубой.

Охлаждение корпуса герметичного компрессора достигается принудительной циркуляцией в машинном отсеке, который засасывается вентилятором через правую часть передней решетки (рис. 2.г) и выбрасывается из отсека в помещение через левую часть решетки.

Система охлаждения масла в компрессоре получила широкое распространение в зарубежных и отечественных холодильниках, реализующий «тропический» температурный 
режим работы [6]. В них охлаждение достигается испарением жидкого хладона, поступающего из предконденсатора в змеевик, который размещен в масляной ванне кожуха компрессора.

Калориметрические исследования, проведенные Мажейкяйским заводом компрессоров и Российским государственным университетом туризма и сервиса (ранее «МТИ») [5] показывают, что компрессора с серийным производством серии «С-КО - OC» с охлаждением масленой ванны хладоном в жидком состоянии из предконденсатора, что может увеличить холодопроизводительность в пределах $3 \div 4,5 \%$, коэффициент эффективности (СОР) на $3 \div$ $4 \%$, причем, потребляемая мощность практически остается постоянной. Температура обмотки электродвигателя понижается на $15 \div 20^{\circ} \mathrm{C}$ в зависимости от площади предконденсатора. Данные показатели не являются высокоэффективными и требую дальнейшего совершенствования и поиска конструктивного решения [7].

Техническая проблема, заключается в разработке и исследовании эффективности системы охлаждения компрессора, позволяющей усилить звукоизоляцию компрессора

Разработана система охлаждения головки компрессора жидким хладоном из предконденсатора [6], представленная на рис 3. Исследование данной системы [8] показывает, что процесс охлаждения элементов компрессора из предконденсатора производится жидким хладоном в так называемом калориметрическом режиме [4] в номинальных параметрах и обеспечивает: повышение холодопроизводительности и коэффициент эффективности соответственно на $9 \div 16 \%$ и $15 \div 20 \%$; снизить температуру обмотки электродвигателя на $21 \div 25 \%$; отводить тепловую энергию работы сжатия через предконденсатор в окружающую среду при ее температуре $60^{\circ} \mathrm{C}$.

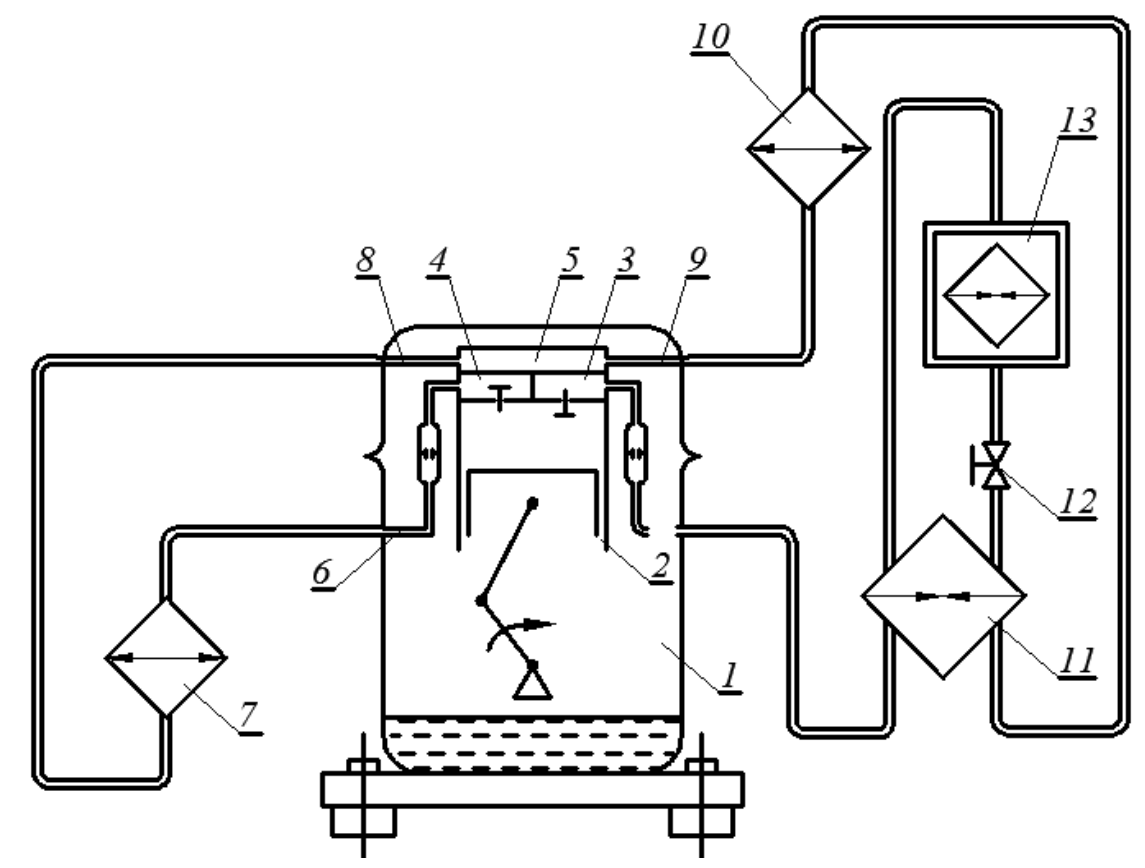

Рисунок 3. Система охлаждения головки компрессора жидким хладоном 1 -ГХК; 2 - цилиндр; 3 - камера всасывания; 4 - камера нагнетания;

5 - головка блока ичлиндра; 6 -змеевик вывода паров хладагента из компрессора (нагнетательный змеевик); 7 - форконденсатор; 8 - змеевик ввода в головку блока циилндра жидкого хладона; 9 - змеевик отвода паров хладагента из ичилиндра;

10 - конденсатор холодильного агрегата; 11 - регенеративный теплообменник;

$$
12 \text { - капиллярная трубка; } 13 \text { - испаритель. }
$$


Объектом, исследования является герметичный компрессор С-КО120H5 (рис 4) производства Барановичский станкостроительный завод (Белоруссия), холодопроизводительностью 123 Вт, включенного в холодильной агрегат «Атлант» с предконденсатором, из которого жидкий хладон по гибкому змеевику подается в герметичную полость, установленную на головке блока цилиндров, где хладов кипит под давлением конденсации интенсивно охлаждая детали компрессора (рис. 4).

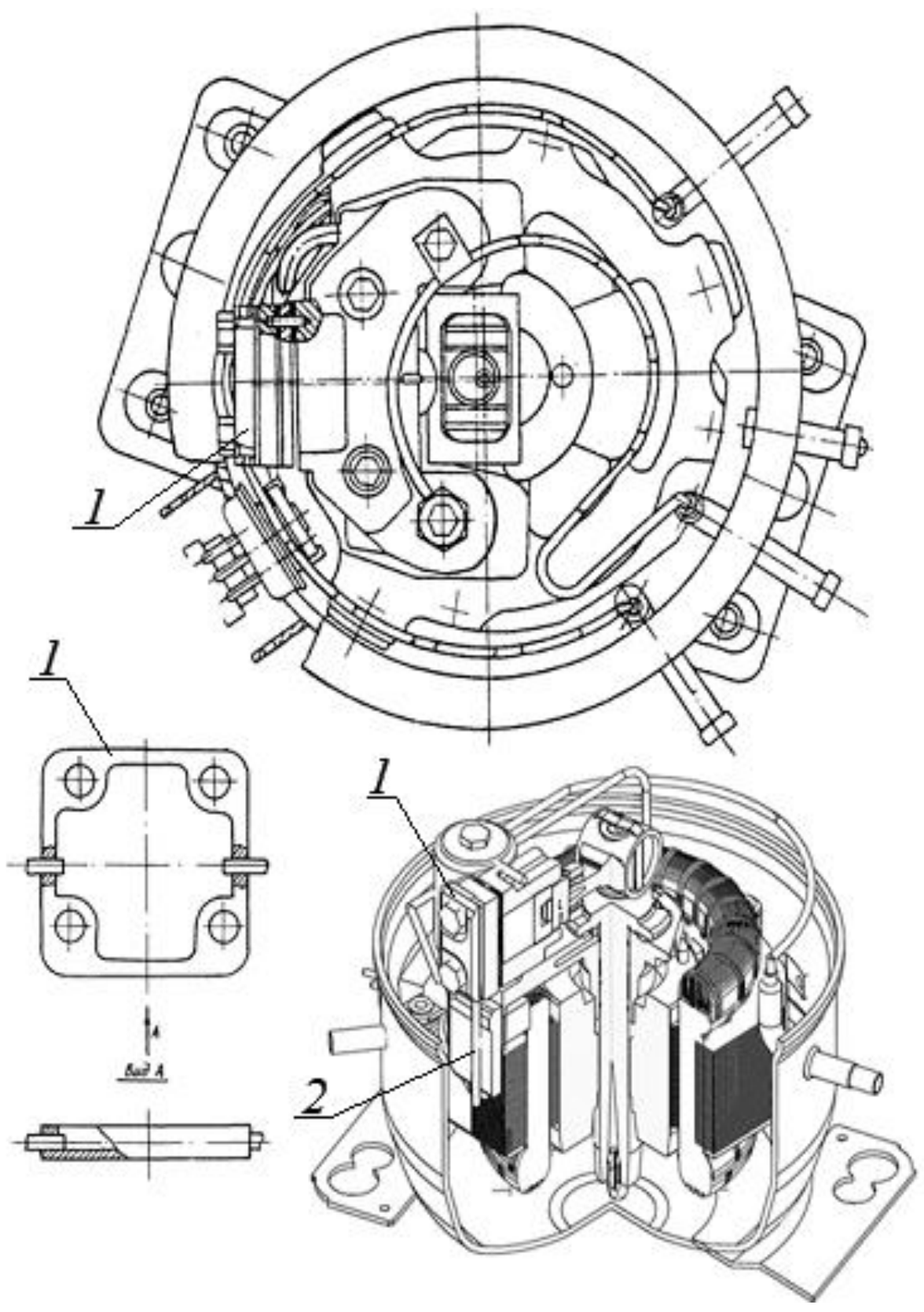

Рисунок 4. Герметичный компрессор пориневого типа для бытовой холодильной техники с охлаждением головки блока ицииндра [6].

1 - головка блока циилиндра; 2 - змеевик отвода паров хладагента из изилндра

Головка охлаждения цилиндра конструктивно представляет собой элемент с выфрезерованной частью для ограничения подъема нагнетательного клапана. Установленная перегородка разделяет всасывающую и нагнетательную полости. Хладагент для охлаждения головки цилиндра подается через гибкие стальные змеевики. 
Нормированным [3,7] испытаниям на калориметрическом стенде подвергались компрессора с охлаждением головки блока цилиндра и звукоизолированной наружной поверхности кожуха компрессора.

Испытаниям подвергались две модификации холодильного агрегата в калориметрическом цикле, представленных на рисунке 5.

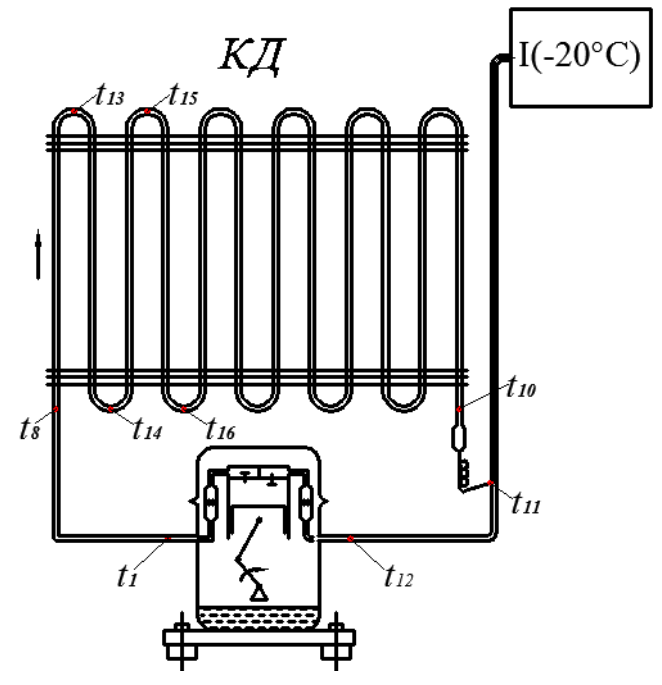

a)

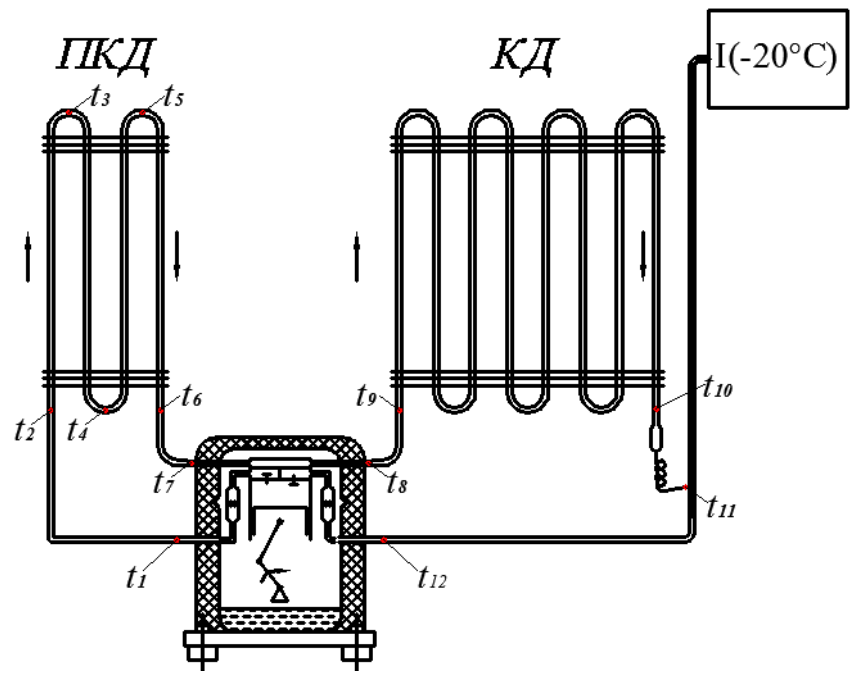

б)

Рисунок 5. Модификации исследуемьх схем холодильного агрегата

а) вариант 1 холодильный агрегат серийного исполнения без системь охлаждения (площадь конденсатора $F_{\text {кд }}=0,776 \mathrm{M}^{2}$ );

б) вариант 2 холодильный агрегат включает компрессор с головкой охлаждения (предконденсатор площзадью $F_{\text {пкд }}=0,26 \mathrm{M}^{2}$ и конденсатор площадью $F_{\mathrm{\kappa д}}=0,52 \mathrm{M}^{2}$ ). Iиспаритель, КД-конденсатор, ПКД-предконденстаор.

Звукоизоляция кожуха компрессора в холодильном агрегате была выполнена в виде технологического колпака рис 4., изготовленного из пенополиуретана с толщиной стенок $20 \div$ 30 мм, которым накрывался компрессор, установленный на пенополиуретановой подставке толщиной 50 мм, В колпаке для труб, соединяющих компрессор с конденсатором и предконденсатором, вырезано окно размером $190 \times 170$ мм. Наружный диаметр колпака 280 мм, высота 260 мм.

Холодильный агрегат, выполненный по варианту 2 испытывался дважды: со звукоизоляцией кожуха компрессора и без нее при температуре окружающей среда $32{ }^{\circ} \mathrm{C}$ и $43^{\circ} \mathrm{C}$. Результаты представлены на рис. 5a. 


\section{Результаты испытаний}

Основные результаты калориметрических испытании компрессора со звукоизоляцией и без звукоизоляции кожуха компрессора (рис 5) и представлены на рис. 6. Анализ результатов калориметрирования компрессора со звукоизоляцией и без звукоизоляции кожуха компрессора позволяет сделать следующие выводы:

a) использование системы охлаждения жидким хладагентом из предконденсатора головки блока цилиндра обеспечивает изолирование кожуха компрессора от окружающей среды звукоизолирующим материалом, практически без нарушения его температурного режима и потери холодопроизводительности;

б) введение звукоизоляции позволит снизить уровень шума на величину определяемую толщиной и эффективностью звукоизолирующего материала.

Результаты испытаний холодильных агрегатов (варианты 1 и 2) в калориметрическом цикле представлены на рис 6 а.

На рис. 6 представлен график изменения температурного поля предконденсатора и конденсатора холодильного агрегата в режиме калориметрирования с устройством для охлаждения блока цилиндров со звукоизоляцией и без звукоизоляции кожуха компрессора при температуре окружающей среды $32^{\circ} \mathrm{C}$ и $43^{\circ} \mathrm{C}$.

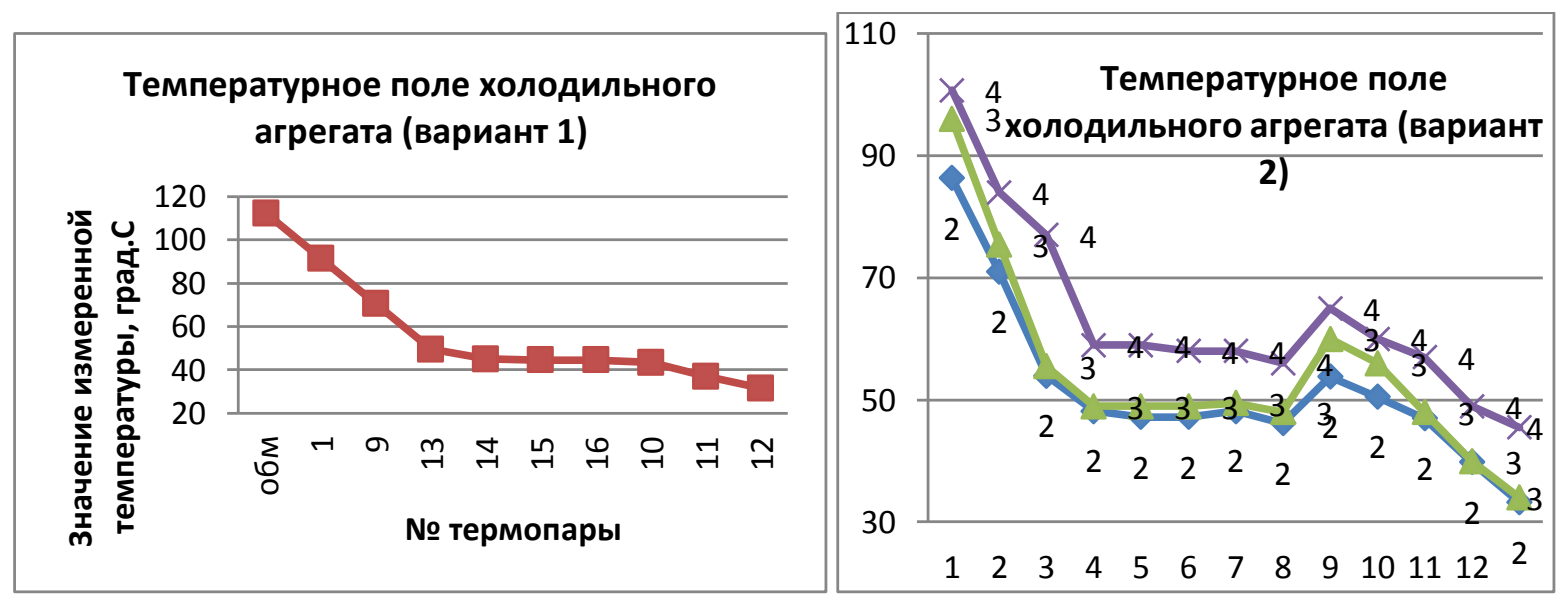

Рисунок 6а. Результаты исследования температурного поля холодильного агарегата

(1-1) - характер изменения температуры хладона в конденсаторе (вариант 1) при температуре окружающем среды $32^{\circ} \mathrm{C}$ без звукоизоляции кожуха компрессора;

(2-2) и (3-3) - характер изменения температуры хладона в предконденсаторе, головке охлаждения и конденсаторе (вариант 2) при температуре окружающей среды $32{ }^{\circ} \mathrm{C}$ без звукоизоляции кожуха компрессора (2-2) и со звукоизоляцией кожуха компрессора (3-3); 


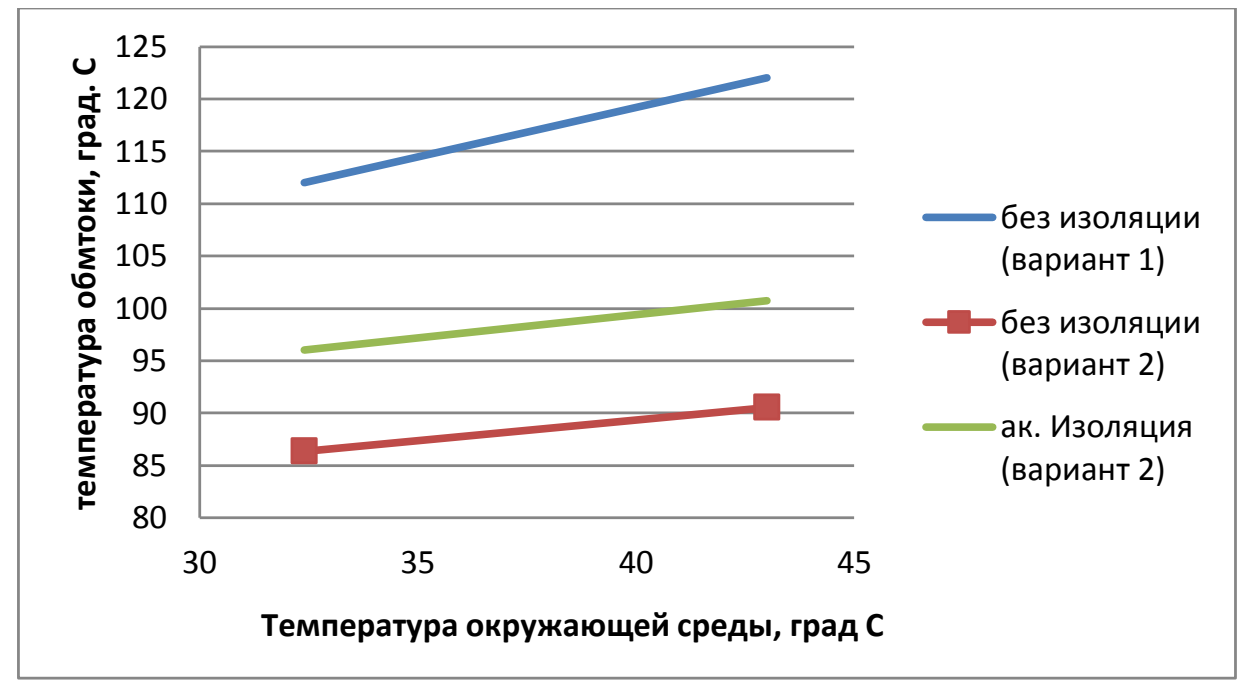

Рисунок бб. Зависимость температуры окружающей среды от температуры обмоток компрессора

Варианты холодильных агрегатов испытывались при оптимальных дозах хладона и постоянной проходимости капиллярной трубки 6,2 \pm 0,2 л/мин. Оптимальная доза хладона подбиралась для каждого варианта по температуре окружающей среды $32{ }^{\circ} \mathrm{C}$ и $43{ }^{\circ} \mathrm{C}$ без изоляции кожуха компрессора. При установке звукоизоляции кожуха, компрессора доза хладона не подбиралась, а оставалась прежней, как и при испытании холодильного агрегата без звукоизоляции кожуха компрессора.

Анализ результатов исследования показывает, что при температурах $32{ }^{\circ} \mathrm{C}$ и $43{ }^{\circ} \mathrm{C}$ как со звукоизоляцией, так и без звукоизоляции кожуха компрессора наблюдается увеличение $Q_{0}, K e$, снижение температуры рабочей обмотки при увеличении площади предконденсатора.

Звукоизоляция кожуха компрессора приводит к некоторому снижению $Q_{0}, K e$, повышению температуры рабочей обмотки электродвигателя. Вероятно, оптимизация дозы хладона при звукоизоляции кожуха компрессора позволит увеличить значение этих показателей.

Из представленных зависимостей следует, что звукоизоляция кожуха компрессора приемлема при эксплуатации холодильного агрегата при температурах не превышающих $32{ }^{\circ} \mathrm{C}$. Для температур $43^{\circ} \mathrm{C}$ эксплуатация холодильных агрегатов возможна (рекомендуемая площадь предконденсатора $F_{\text {пкд }}=0,64 \mathrm{M}^{2}$ ).

На рис. 7 приведены сравнительные результаты корректированного уровня звуковой мощности холодильников МХМ-268 в 1/3 октавном диапазоне частот с системой охлаждения головки блока цилиндра и звукоизоляцией и без звукоизоляцией кожуха компрессора. 


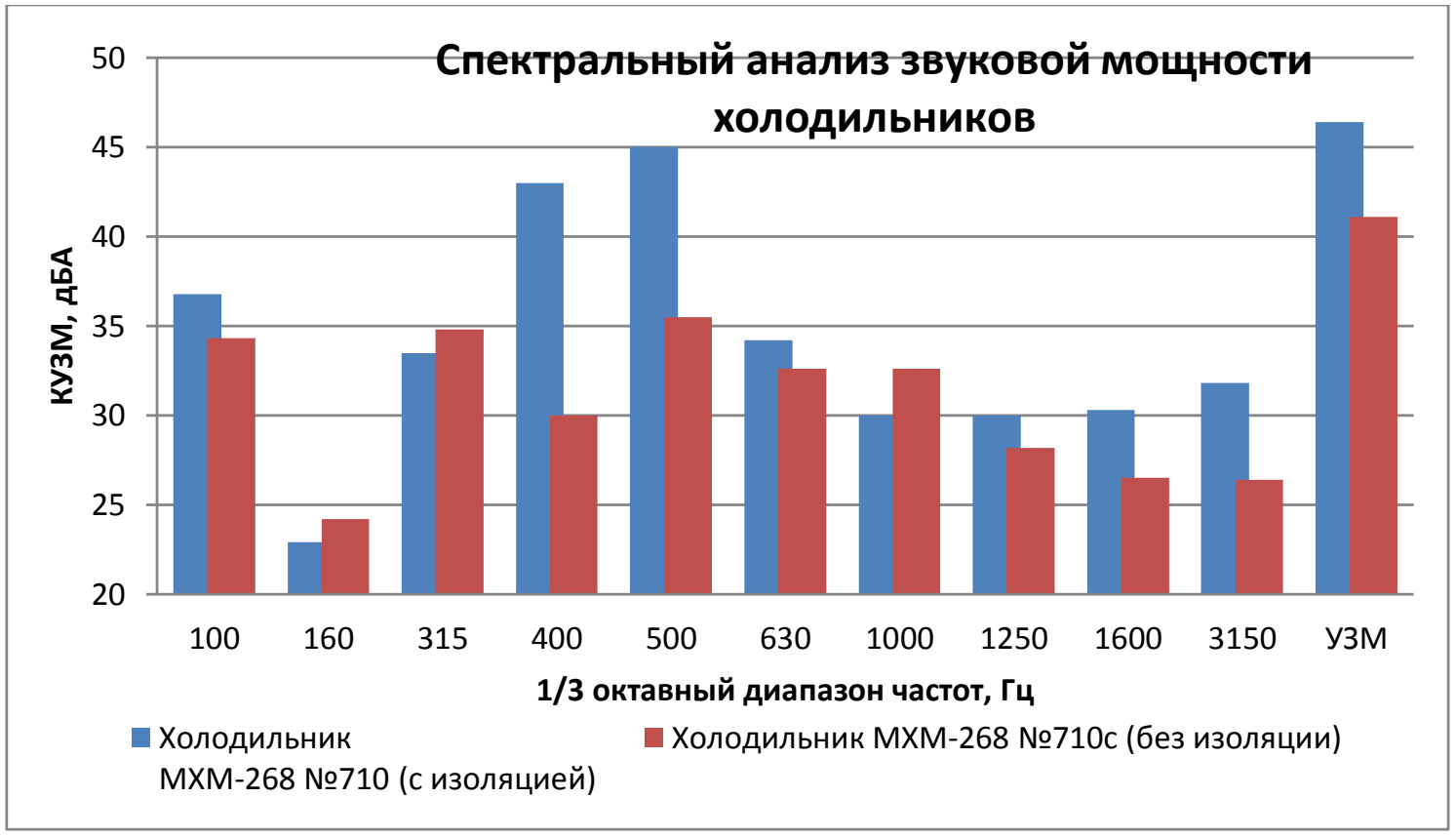

Рисунок 7. Сравнительный анализ корректированного уровня звуковой мощности холодильников в 1/3 октавном диапазоне частот

\section{Заключение}

1. Калориметрические испытания компрессора с системой охлаждения жидким хладоном из предконденсатора головки блока цилиндра показали, что значения холодопроизводительности, потребляемой мощности и температуры обмоток электродвигателя позволяют звукоизолировать кожух компрессора изолирующим материалом.

2. Холодопроизводительность, холодильный коэффициент компрессора с охлаждением головки блока цилиндра и звукоизолированным кожухом выше, чем у компрессора без системы охлаждения соответственно на 1 и 10\%, а температура рабочей обмотки и уровень звуковой мощности ниже соответственно на 17\% и 11\%.

3. Температура рабочей обмотки компрессора с охлаждением головки блока цилиндра и звукоизолированным кожухом не превышает $100{ }^{\circ} \mathrm{C}$ при Токр. воз. $=32^{\circ} \mathrm{C}$ и $105^{\circ} \mathrm{C}$.

4. Корректированный уровень звукового мощности бытового холодильника LG модели GA-B409SLQA со звукоизолированным щитком перед компрессором (рис 2.г), определенный по ГОСТ 30163.0-95 составил 47,56 дБА. На основе представленных результатов, можно полагать, что применение отвода теплоты от головки блока цилиндра компрессора [5], где можно использовать рекомендации по управлению процессом [9], позволит повысить звукоизолирующую и звукоотражающую спососбность пластины и тем самым снизить уровень шума холодильника и повысить его энергоэффнективность. 


\section{ЛИТЕРАТУРА}

1. Деменев А. В. Снижение шума клапанного механизма поршневого компрессора для бытовой холодильной техники [Текст]: автореф. дис. канд. тех. наук: 05.02.13 / А. В. Деменев; [Место защиты: Рос. гос. ун-т туризма и сервиса]. - Москва, 2008.-22 c.

2. Иванов В.А., Шагунов Д.В., Байкин С.Д. Модернизация оборудования сервиса как способ расширения его технологических возможностей [Текст]: / Электротехнические и информационные комплексы и системы № 2, т. 8, 2012 г. C.2-8

3. Исследование и разработка энергоэффективной бытовой холодильной техники, работающей при температуре окружающей среды до 60 град. С [Текст]: / А.И. Набережных, А.В. Деменев // Госбюджетная НИР: ГБ-ФС-04-12. - М, Изд-во ФГБО ВПО «РГУТиС», - 2012

4. Компрессоры холодильные. Условия испытаний по определению основных характеристик, допуски и представление данных производителями // Refrigerant compressors. Rating conditions, tolerances and presentation of manufacturer's performance data [Текст]: ГОСТ Р 54381-2011 (ЕН 12900:2006) / дата введения 2012-01-01. - М.: Стандартинформ, 2011. - 14 С.

5. Компрессионная холодильная установка: авторское свидетельство № 1000693 Рос. Федерация: МКИ 4 F 25 В 1/00. / А. И. Набережных, О. П. Голубев, А. В. Максимов. - 3354991/23-03; Заявл. 19.11.81; опубл. 28.02.83, Бюл. № 8. - 2 С.

6. Оборудование и технология ремонта бытовой техники: Учеб. пособие для студентов вузов./Болгов И. В., Набережных А. И., Фишман Б. Е., Баринов В. В.М.: Легкая индустрия, 1978. $311 \mathrm{c.}$

7. Тимошенко М.В., Гараз Т.В., Пономарева Ю.Н. Числовые характеристики распределения при обработке результатов эксперимента [Текст]: / Электротехнические и информационные комплексы и системы. - 2010. - Т.6, №2. - C. 42-46.

8. Холодильник бытовой электрический «ЗиЛ-63» КШ-260 ТУ 27-56-949-92 [Текст]: Руководство по эксплуатации. - М.: Машиностроение, 1984 - 16с.

9. A. Kazantsev, J. Ponomareva, P. Kazantsev, R. Digilov, andP. Huang. Development of e-health network for in-home pregnancy surveillance based on artificial intelligence. // Proc. of the IEEE-EMBS International Conference on Biomedical and Health Informatics (BHI 2012), Hong Kong and Shenzhen, China, 2-7 Jan 2012. - P. 82-84.

10. Demenev AV Noise reduction valve mechanism piston compressor for household refrigerators [Text]: Author. dis. Candidate . those . Sciences: 05.02.13 / AV Demenev ; [a protection Place : Ros. Reg. Univ of tourism and service ] . - Moscow, 2008. -22 .

11. Household electric refrigerator " ZIL- 63 " SH -260 TU 27-56-949-92 [Text] : User Manual . - M.: Mashinostooenie , 1984 - 16c .

12. Equipment and technology for repair of household appliances : Proc . manual for students . / Bolgov IV, Naberezhnye AI , B. E. Fishman, Bari - new B. V.-M. : Light industry, 1978.311 . 
13. Refrigerating compressors . Terms of tests to determine the basic characteristics , tolerances and presentation of data producers / / Refrigerant compressors. Rating conditions, tolerances and presentation of manufacturer's performance data [ text ] : GOST R 54381-2011 ( EN 12900:2006 ) / implementation date 2012-01-01 . - M.: Standartinform 2011. - 14 C.

14. Research and development of energy-efficient household refrigeration equipment operating at ambient temperatures up to 60 degrees. With [ Text] / A. Embankments, AV Demenev / / State program is : GB - PS -04-12 . - M, Izd VPO " RSUTS " - 2012

15. Compression refrigeration system : copyright certificate number 1000693 Ros. Federation: MKI 4 F 25 in 1/00 . / AI Naberezhnye , A. Golubev , AV Maximov . 3354991/23-03 ; Appl . 19.11.81, publ . 02.28.83, Bull . Number 8. - 2 C.

Рецензент: Комаров Николай Михайлович, доктор экономических наук, профессор, член редколлегии журнала. 
Demenev Alexey Vladimirovich

Russian State University of Tourism and Service" (RSUTS)

Russia, Moscow

E-mail: saprmgus@mail.ru

Naberezhnykh Anatoly Ivanovich

Russian State University of Tourism and Service" (RSUTS)

Russia, Moscow

E-mail: ntchausehold@gmail.com

Danilov Artem Igorevich

Russian State University of Tourism and Service" (RSUTS)

Russia, Moscow

E-mail:danilov.tema@mail.ru

\title{
Noise reduction by household refrigerator for compressor cooling
}

\begin{abstract}
In the household refrigerator compressor is the main source of noise and heat, and the isolation of sound from the compressor in the air increases the thermal stress of his work and a significant reduction of energy efficiency of the refrigerator. Installing sound insulation panel in front of the compressor housing to reduce the noise level. The cooling system compressor oil is widely used in foreign and domestic refrigerators, implements "tropical" operating temperature Options refrigeration units tested at optimal doses of freon and constant permeability of the capillary tube. Soundproofing compressor housing leads to some increase in temperature of the motor windings and optimization of dose refrigerant with soundproofed compressor housing will increase the value of these indicators. The results confirm the possibility of reducing the noise of the refrigerator, through the use of an optimized heat removal from the cylinder head of the compressor.
\end{abstract}

Keywords: positive displacement hermetic compressor; cooling system; refrigerating capacity; superheat; coefficient of performance; corrected sound power level. 


\section{REFERENCES}

1. Demenev A. V. Snizhenie shuma klapannogo mekhanizma porshnevogo kompressora dlya bytovoy kholodil'noy tekhniki [Tekst]: avtoref. dis. kand. tekh. nauk: 05.02.13 / A. V. Demenev; [Mesto zashchity: Ros. gos. un-t turizma i servisa]. - Moskva, 2008.-22 s.

2. Ivanov V.A., Shagunov D.V., Baykin S.D. Modernizatsiya oborudovaniya servisa kak sposob rasshireniya ego tekhnologicheskikh vozmozhnostey [Tekst]: / Elektrotekhnicheskie i informatsionnye kompleksy i sistemy № 2, t. 8, 2012 g. S.2-8

3. Issledovanie i razrabotka energoeffektivnoy bytovoy kholodil'noy tekhniki, rabotayushchey pri temperature okruzhayushchey sredy do 60 grad. S [Tekst]: / A.I. Naberezhnykh, A.V. Demenev // Gosbyudzhetnaya NIR: GB-FS-04-12. - M, Izd-vo FGBO VPO «RGUTiS», - 2012

4. Kompressory kholodil'nye. Usloviya ispytaniy po opredeleniyu osnovnykh kharakteristik, dopuski i predstavlenie dannykh proizvoditelyami // Refrigerant compressors. Rating conditions, tolerances and presentation of manufacturer's performance data [Tekst]: GOST R 54381-2011 (EN 12900:2006) / data vvedeniya 2012-01-01. - M.: Standartinform, 2011. - 14 S.

5. Kompressionnaya kholodil'naya ustanovka: avtorskoe svidetel'stvo № 1000693 Ros. Federatsiya: MKI 4 F 25 V 1/00. / A. I. Naberezhnykh, O. P. Golubev, A. V. Maksimov. - 3354991/23-03; Zayavl. 19.11.81; opubl. 28.02.83, Byul. № 8. - 2 S.

6. Oborudovanie i tekhnologiya remonta bytovoy tekhniki: Ucheb. posobie dlya studentov vuzov./Bolgov I. V., Naberezhnykh A. I., Fishman B. E., Barinov V. V.-M.: Legkaya industriya, 1978. $311 \mathrm{~s}$.

7. Timoshenko M.V., Garaz T.V., Ponomareva Yu.N. Chislovye kharakteristiki raspredeleniya pri obrabotke rezul'tatov eksperimenta [Tekst]: / Elektrotekhnicheskie i informatsionnye kompleksy i sistemy. - 2010. - T.6, №2. - S. 42-46.

8. Kholodil'nik bytovoy elektricheskiy «ZiL-63» KSh-260 TU 27-56-949-92 [Tekst]: Rukovodstvo po ekspluatatsii. - M.: Mashinostroenie, 1984 - 16s.

9. A. Kazantsev, J. Ponomareva, P. Kazantsev, R. Digilov, andP. Huang. Development of e-health network for in-home pregnancy surveillance based on artificial intelligence. // Proc. of the IEEE-EMBS International Conference on Biomedical and Health Informatics (BHI 2012), Hong Kong and Shenzhen, China, 2-7 Jan 2012. - P. 82-84.

10. Demenev AV Noise reduction valve mechanism piston compressor for household refrigerators [Text]: Author. dis. Candidate . those . Sciences: 05.02.13 / AV Demenev ; [a protection Place : Ros. Reg. Univ of tourism and service ] . - Moscow, 2008. -22 .

11. Household electric refrigerator " ZIL- 63 " SH -260 TU 27-56-949-92 [Text] : User Manual . - M.: Mashinostooenie , 1984 - 16c .

12. Equipment and technology for repair of household appliances : Proc . manual for students . / Bolgov IV, Naberezhnye AI , B. E. Fishman, Bari - new B. V.-M. : Light industry, 1978.311 .

13. Refrigerating compressors . Terms of tests to determine the basic characteristics , tolerances and presentation of data producers / / Refrigerant compressors. Rating conditions, tolerances and presentation of manufacturer's performance data [ text ] : 
GOST R 54381-2011 ( EN 12900:2006 ) / implementation date 2012-01-01 . - M.: Standartinform 2011. - 14 C.

14. Research and development of energy-efficient household refrigeration equipment operating at ambient temperatures up to 60 degrees. With [ Text] / A. Embankments, AV Demenev / / State program is : GB - PS -04-12 . - M, Izd VPO " RSUTS " - 2012

15. Compression refrigeration system : copyright certificate number 1000693 Ros. Federation: MKI 4 F 25 in 1/00 . / AI Naberezhnye , A. Golubev , AV Maximov . 3354991/23-03 ; Appl . 19.11.81, publ . 02.28.83, Bull . Number 8. - 2 C. 